\title{
AN INTEGRATED FUZZY MULTI CRITERIA GROUP DECISION MAKING MODEL FOR HANDLING EQUIPMENT SELECTION
}

\author{
Abdolreza YAZDANI-CHAMZINI \\ South Tehran Branch, Islamic Azad University, Tehran, Iran \\ Received 21 Mar 2012; accepted 09 Oct 2012
}

\begin{abstract}
The problem of handling equipment selection plays a significant role in the total cost of a mining project; so that it can affect the activity and continuity of the project and is a strategic problem. In this study, an integrated model based on two fuzzy multi-criteria decision making techniques for handling equipment selection is proposed. The proposed evaluation model is derived from group decision making, fuzzy set theory, analytical hierarchy process (AHP), and Technique to Order Preference by Similarity to Ideal Solution (TOPSIS) methods. The fuzzy AHP (FAHP) method is utilized to calculate the relative importance of the evaluation criteria, then, fuzzy TOPSIS (FTOPSIS) is applied for evaluating the feasible handling equipment in order to select the best handling system among a pool of the possible alternatives. The model is applied for a real world case study to demonstrate the capability and effectiveness of the proposed model. To investigate the result sensitiveness to the changes of the criteria weights, a sensitivity analysis is finally conducted.
\end{abstract}

Keywords: handling equipment selection, group decision making, FAHP, FTOPSIS.

\section{Introduction}

Equipment selection plays a key role in mining design due to the fact that an inappropriate selection can negatively affect the overall cost and continuity of a mine. Loading and handling equipment are among the most crucial operation impacting production in surface and underground mines and have a substantial share of a total mine costs (Sayadi et al. 2012). Material handling can account for $30-75 \%$ of the total cost, and efficient material handling can be primarily responsible for reducing the operating cost by 15-30\% (Sule 1994; Kulak 2005). Therefore, the outputs of the project depend on the type of selected equipment for handling. Since a wider range of equipment are available today, determination of the best equipment for a given production environment is not an easy task (Paramasivam et al. 2011).

The problem of handling equipment selection is a multi criteria decision making (MCDM) issue because it comprises a set of effective criteria that are often in conflict with each other. There are many ways to classify the existing MCDM methods (Zavadskas, Turskis 2011). Belton and Stewart (2002) grouped the MCDM methods into three main categories: (1) value measurement model such as analytical hierarchy process (AHP); (2) outranking models such as Preference Ranking Organization Method for Enrichment Evaluation (PROMETHEE); and (3) goal aspiration and reference level models such as Technique to Order Preference by Similarity to Ideal Solution (TOPSIS).
TOPSIS is one of the most popular methods for solving the MCDM problems (Liu 2009; Tupenaite et al. 2010; Han, Liu 2011; Kalibatas et al. 2011). This method takes into account the ideal and the anti-ideal solutions simultaneously to select the best alternative among a pool of feasible alternatives. However, TOPSIS is often criticized for its inability to deal with vague and uncertain problems ( $\mathrm{Yu}$ et al. 2011); so that, without considering the inherent uncertainty and/or imprecision of the elements could result in unreliable and unrealistic assessment. On the other hand, fuzzy logic is capable of handling the existing uncertainty. This technique uses linguistic variable instead of traditional quantitative expression, which is a very helpful concept for dealing with situations which are too complex or insufficiently defined (Zadeh 1965). According to Fouladgar et al. (2011), fuzzy TOPSIS (FTOPSIS) has different advantages, including logical concepts, simple and fast computations, and tolerating the uncertainty. Hence, FTOPSIS is recently employed in order to solve different aspects of priority problems, such as strategy management (Wu et al. 2010; Fouladgar et al. 2011), equipment selection (Lashgari et al. 2011; Yazdani-Chamzini, Yakhchali 2012), risk management (Wang, Elhag 2006; Kutlu, Ekmekçioğlu 2012; Fouladgar et al. 2012b), service quality (Awasthi et al. 2011b; Büyüközkan, Çifçi 2012), supply chain management (Boran et al. 2009; Liao, Kao 2011; Jolai et al. 2011), and sustainability evaluation (Awasthi et al. 2011a; Awasthi, Chauhan 2012). 
Moreover, Fuzzy AHP (FAHP) is widely used for solving MCDM problems in real situations (Fouladgar et al. 2011). In this paper, FAHP is integrated with FTOPSIS under group decision making to select the optimum handling system among a set of the feasible alternatives. First FAHP is employed to determine the relative importance of the evaluation criteria. Then by applying the weight vector of the evaluation criteria obtained in previous stage, FTOPSIS is used to acquire the final ranking order of handling methods.

The rest of the paper is organized as follows: past researches effort to prioritize and select the handling equipment is summarized in Section 1. Section 2 presents the basic descriptions of fuzzy set theory, FAHP method, and FTOPSIS technique. Stages of the proposed evaluation model are explained in Section 3. Section 4 illustrates a real world case study of handling equipment selection in an open pit mine. Finally, conclusions and findings are discussed in the last section.

\section{Literature review}

According to the importance of handling, a large number of researchers have applied different approaches for solving the problem of the handling equipment selection. Chan et al. (2001) developed an intelligent material handling equipment selection system called Material Handling Equipment Selection Advisor (MHESA). The MHESA contains three parts: (1) a database to store equipment types with their specifications; (2) a knowledge-based expert system for assisting material handling equipment selection; and (3) an AHP (analytical hierarchy process) model to select the most favourable equipment type.

Park (1996) proposed an intelligent knowledgebased expert system called ICMESE for the selection and evaluation of material handling equipment suitable for movement and storage of materials in a manufacturing facility. Chakraborty and Banik (2006) developed an AHP for designing a material handling equipment selection model. They used pairwise comparison matrices to measure the relative importance of each criteria, subcriteria and sub-subcriteria and then determined the overall ranking of each alternative equipment.

Chu et al. (1995) developed a computer-assisted methodology for the selection of the suitable material handling equipment. Onut et al. (2009) proposed a combined MCDM methodology for evaluation and selection of material handling equipment (MHE) types for a company in the steel construction industry in Istanbul, Turkey. Mirhosseyni and Webb (2009) proposed a hybrid fuzzy knowledge-based expert system and genetic algorithm for efficient selection and assignment of material handling equipment.

Poon et al. (2011) proposed a RFID-GA-based warehouse resource allocation system (RGWRAS) for handling stochastic production material demand problems and for allocating warehouse resources on the shop floor and in warehouse environments. Fisher et al. (1988) proposed a rule-based expert system called MATHES for material handling equipment selection. A systematic pro- cedure for the selection of bulk material handling equipment is proposed by Velury and Kennedy (1992). This paper concentrates on the selection of relevant factors that need to be taken into account in the design of a bulk material handling system and on the selection of equipment once these factors have been considered. Fonseca et al. (2004) applied a knowledge-based system for conveyor equipment selection.

Bazzazi et al. (2011b) proposed a new method of MCDM that is applied to select the suitable loadinghaulage equipment for the open pits mines. Bazzazi et al. (2011a) presented an evaluation model based on deterministic data, fuzzy numbers, interval numbers and linguistic terms to select loading-hauling system for an iron ore open pit mine. In this model, a combination of AHP and entropy method was applied for attribute weighting and VIKOR was employed to rank the feasible alternatives.

Lashgari et al. (2012) proposed a new integrated model based on ANP, fuzzy AHP, and TOPSIS to choose the best alternative among possible loading and hauling systems. Mahdavi et al. (2011) developed a bi-objective operation allocation and material handling equipment selection problem in flexible manufacturing system (FMS) with the aim of minimizing the machine operation, material handling and machine setup costs and maximizing the machine utilization. Anand et al. (2011) developed an AHP for the selection of material handling systems in the design of FMS. Tuzkaya et al. (2010) proposed an integrated fuzzy multi-criteria decision making methodology for material handling equipment selection problem (MHESP). In this paper, evaluation criteria for the MHESP is weighted by fuzzy-ANP (F-ANP) approach, then, alternative material handling equipments are evaluated by fuzZy-PROMETHEE (F-PROMETHEE) approach.

The selection of a loading-hauling system using an AHP-based model was evaluated by Bascetin (2004) for coal production in an open pit coal mine located Orhaneli, in western Turkey. Yaman (2001) proposed a knowledge-based approach for selection of material handling equipment and material handling system pre-design. Denby and Schofield (1990) developed the MINDER system (MINe Design using Expert Reasoning) for surface mining method selection and excavation and haulage equipment selection.

According to incomplete data, less or even lack of information, and inherent complexity, most of the abovementioned studies have neglected this problem. Fuzzy set theory is a powerful tool to handle the inherent uncertainty. Moreover, knowledge-based expert systems have some disadvantages, such as the doubts left due to the difficulties in defining many rules.

On the one hand, based on the past researches, it is clear that FTOPSIS has demonstrated its capabilities and efficiencies as a practical engineering and problemsolving tool. On the other hand, FAHP is the most popular technique for solving the MCDM problems. Likewise, by using group decision making (social choice), different rating viewpoints and the tradeoffs among different criteria are taken into consideration in the aggregation procedure to ensure more accurate decision making (Karsak 
2002). This makes that the group decision making is attracting more and more attention in management, and has received a great deal of attention from researchers (Yue 2011). In this paper, an integrated model based on FTOPSIS and FAHP methods under group decision making is proposed to select the most appropriate handling equipment. First, FAHP is utilized to obtain the weights of the evaluation criteria, then, by using the weight vector obtained in the first step, FTOPSIS is used to select the best handling system.

\section{Mathematical background}

\subsection{Fuzzy set theory}

Complexity is an important part of most real world decision problems that is due to the existing uncertainty, imprecise knowledge, and less of information. The use of the techniques and tools that allow the available information to be used with the adequate guaranty is desired for dealing with such complexity. Fuzzy set, introduced by Zadeh (1965), is a powerful tool for capturing the uncertainty and vagueness under the conditions of imprecise and incomplete information. Fuzzy theory reflects human reasoning in its use of approximate information and uncertainty to generate decisions (Wong, Lai 2011).

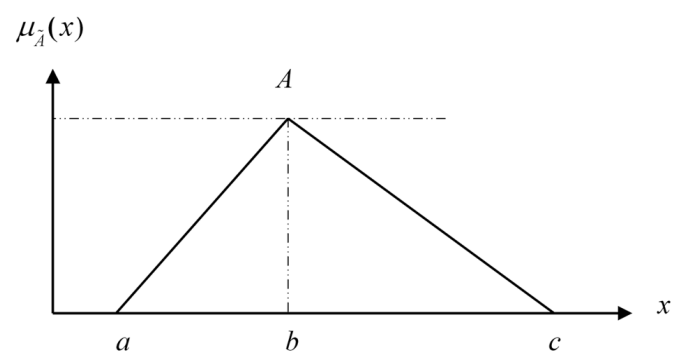

Fig. 1. Triangular fuzzy number

A triangular fuzzy number (TFN) is defined as $\tilde{A}=(a, b, c)$; which $a, b$, and $c$ are crisp numbers and $a \leq b \leq c$. A fuzzy number is defined by its membership function whose values can be any number in the interval $[0,1]$, which 0 expresses do not belong to the set under consideration and 1 addresses full belong to the set. Assume that TFNs start rising from zero at $x=a$; reach a maximum of 1 at $x=b$; and decline to zero at $x=c$ as shown in Figure 1. Then the membership function $\mu_{\tilde{A}}(x)$ of a TFN is given by:

$$
\mu_{\tilde{A}}(x)=\left\{\begin{array}{ll}
0, & x<a \\
(x-a) /(b-a), & a \leq x<b \\
(x-c) /(b-c), & b \leq x<c \\
0, & x>c
\end{array} .\right.
$$

Let $\tilde{a}=\left(a_{1}, b_{1}, c_{1}\right)$ and $\tilde{b}=\left(a_{2}, b_{2}, c_{2}\right)$ be two TFNs then the vertex method is defined to compute the distance between them by Eqn (2):

$d(\tilde{a}, \tilde{b})=\sqrt{\frac{1}{3}\left[\left(a_{1}-a_{2}\right)^{2}+\left(b_{1}-b_{2}\right)^{2}+\left(c_{1}-c_{2}\right)^{2}\right]}$.

The fuzzy linguistic term is a fuzzy number or a variable whose values are words or sentences in language terms (Fouladgar et al. 2012c). These terms can be divided into different linguistic criteria. A 9-point scale for defining the weights of criteria as presented in Table 1 has been deliberately selected. As well as, a 5-point scale for defining the preference ratings of alternatives is deliberately adopted as given in Table 2 and Figure 2.

Table 2. Linguistic terms for the preference rating of alternatives

\begin{tabular}{cc}
\hline Linguistic term & Corresponding triangular fuzzy number \\
\hline Very poor (VP) & $(0,1,3)$ \\
Poor (P) & $(1,3,5)$ \\
Fair (F) & $(3,5,7)$ \\
Good (G) & $(5,7,9)$ \\
Very good (VG) & $(7,9,10)$ \\
\hline
\end{tabular}

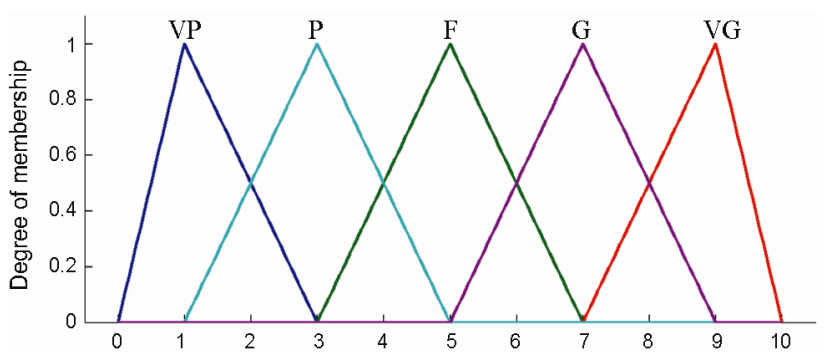

Fig. 2. Membership functions of linguistic values for preference rating

Table 1. Linguistic terms for the importance weights of the criteria

\begin{tabular}{lccc}
\hline \multicolumn{1}{c}{ Linguistic term } & Fuzzy number & Triangular fuzzy scale & Triangular fuzzy reciprocal scale \\
\hline Equal importance (EI) & $\tilde{1}$ & $(1,1,1)$ & $(1,1,1)$ \\
Intermediate (IMI) & $\tilde{2}$ & $(1,2,3)$ & $(1 / 3,1 / 2,1)$ \\
Moderate importance (MI) & $\tilde{3}$ & $(2,3,4)$ & $(1 / 4,1 / 3,1 / 2)$ \\
Intermediate (ISI) & $\tilde{4}$ & $(3,4,5)$ & $(1 / 5,1 / 4,1 / 3)$ \\
Strong importance (SI) & $\tilde{5}$ & $(4,5,6)$ & $(1 / 6,1 / 5,1 / 4)$ \\
Intermediate (IVSI) & $\tilde{6}$ & $(5,6,7)$ & $(1 / 7,1 / 6,1 / 5)$ \\
Very strong importance (VSI) & $\tilde{7}$ & $(6,7,8)$ & $(1 / 8,1 / 7,1 / 6)$ \\
Intermediate (IEXI) & $\tilde{8}$ & $(7,8,9)$ & $(1 / 1,1 / 8,1 / 7)$ \\
Extreme importance (EXI) & $\tilde{9}$ & $(8,9,10)$ & \\
\hline
\end{tabular}




\subsection{FAHP method}

Analytical hierarchy process (AHP), developed by Saaty (1980), is a decision analysis method that takes into account both qualitative and quantitative information. AHP can decompose any complex problem into several subproblems in terms of hierarchical levels where each level represents a set of criteria or attributes relative to each sub-problem. This method utilizes three principles to solve problems (Aydogan 2011): (1) structure of the hierarchy; (2) the matrix of pairwise comparison ratios; and (3) the method for calculating weights.

Despite the popularity of the AHP technique, it is not capable of handling the existing uncertainty and complexity in real world problems. The merit of using a fuzzy approach is to determine the relative importance of attributes using fuzzy numbers instead of precise numbers (Sun 2010; Kara 2011; Yazdani-Chamzini, Yakhchali 2012). There are many fuzzy AHP methods proposed on the basis of the concepts of the fuzzy set theory and hierarchical structure by various researchers to solve the selection problems in different fields of application (Van Laarhoven, Pedrycz 1983; Buckley 1985; Boender et al. 1989; Chang 1996; Cheng 1996).

In this paper, despite the fact Chang's method is relatively easier to implement, Buckley's method is applied for calculating the weights of the evaluation criteria because of some drawbacks of Chang's method (Wang et al. 2008). The FAHP procedure can be defined as follows:

Step 1. Construct pairwise comparison matrices among all the criteria in the dimensions of the hierarchy system. Determine linguistic terms to the pairwise comparisons by asking which is the more important of each two dimensions based on Table 1, as following matrix $\tilde{A}$ :

$$
\tilde{A}=\left[\begin{array}{cccc}
1 & \tilde{a}_{12} & \cdots & \tilde{a}_{1 n} \\
\tilde{a}_{21} & 1 & \cdots & \tilde{a}_{2 n} \\
\vdots & \vdots & \ddots & \vdots \\
\tilde{a}_{n 1} & a_{n 2} & \cdots & 1
\end{array}\right]=\left[\begin{array}{cccc}
1 & \tilde{a}_{12} & \cdots & \tilde{a}_{1 n} \\
1 / \tilde{a}_{12} & 1 & \cdots & \tilde{a}_{2 n} \\
\vdots & \vdots & \ddots & \vdots \\
1 / \tilde{a}_{n 1} & 1 / \tilde{a}_{n 2} & \cdots & 1
\end{array}\right],
$$

where:

$$
\tilde{a}_{i j}=\left\{\begin{array}{lc}
\tilde{9}^{-1}, \cdots, \tilde{2}^{-1}, \tilde{1}, \tilde{2}, \cdots, \tilde{9}, & i \neq j \\
1 & i=j
\end{array} .\right.
$$

Step 2. Calculate the aggregated fuzzy weights of each criterion by geometric mean technique (Buckley 1985) that is:

$$
\begin{gathered}
\tilde{r}_{i}=\left(\tilde{a}_{i 1} \otimes \cdots \tilde{a}_{i j} \otimes \cdots \otimes \tilde{a}_{i n}\right)^{1 / n} ; \\
\tilde{w}_{i}=\tilde{r}_{1} \otimes\left[\tilde{r}_{1} \oplus \cdots \oplus \tilde{r}_{i} \oplus \cdots \oplus \tilde{r}_{n}\right]^{-1},
\end{gathered}
$$

where: $\tilde{a}_{i j}$ is fuzzy comparison value of dimension $i$ to criterion $j$, thus, $\tilde{r}_{i}$ is a geometric mean of fuzzy comparison value of criterion $i$ to each criterion, $\tilde{w}_{i}$ is the fuzzy weight of the $i$ th criterion, can be indicated by a TFN, $\tilde{w}_{i}=\left(l w_{i}, m w_{i}, u w_{i}\right)$. The $l w_{i}, m w_{i}$ and $u w_{i}$ are the lower, middle, and upper values of the fuzzy weight of the $i^{\text {th }}$ dimension.

\subsection{FTOPSIS technique}

The Technique for Order Preference by Similarity to Ideal Solution (TOPSIS), introduced by Hwang and Yoon (1981), is based on the concept that the most appropriate alternative should have the shortest distance from the positive ideal solution (PIS) and the farthest distance from the negative ideal solution (NIS). The PIS is a solution that maximizes the benefit criteria and minimizes the cost criteria simultaneously, whereas the NIS maximizes the cost criteria and minimizes the benefit criteria simultaneously (Yazdani-Chamzini, Yakhchali 2012). This technique was developed as fuzzy TOPSIS (FTOPSIS) to solve ranking and evaluating problems, because fuzzy allows the decision-makers to incomplete information, non-obtainable information into decision model (Kulak et al. 2005). The main steps of the FTOPSIS can be defined as follows:

Step 1. Choose the linguistic variables for the alternatives with respect to the evaluation criteria. The linguistic variables are linguistic terms that express the values by words or sentences. Each linguistic value can be represented by a TFN which can be assigned to a membership function. In this study, we employed TFNs be associated to the linguistic values and scales of five points for the ratings of alternatives (Table 2 and Fig. 2) and nine points for importance weights of the evaluation criteria (Table 1).

Step 2. Construct the fuzzy decision matrix.

To calculate the performance of a set of alternatives on a given set of criteria, the decision matrix of $m \times n$ dimension is formed, which $m$ and $n$ are the number of alternatives and criteria respectively.

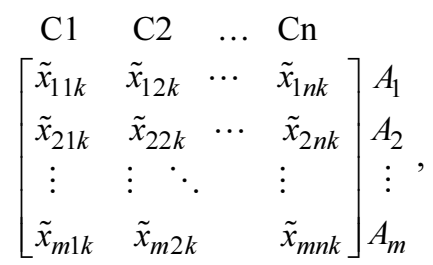

where: $\tilde{x}_{i j k}, i=1,2, \ldots, m ; j=1,2, \ldots, n ; k$ is the number of decision makers, are linguistic triangular Fuzzy numbers, $\tilde{x}_{i j k}=\left(x_{i j k 1}, x_{i j k 2}, x_{i j k 3}\right)$.

Step 3. Aggregate the ratings of alternatives respect to each criterion $\left(\tilde{x}_{i j}\right)$. In order to aggregate the ratings of alternatives versus each criterion, the arithmetic mean is applied.

Let the fuzzy ratings of all decision makers be TFNs $\tilde{x}_{i j k}=\left(x_{i j k 1}, x_{i j k 2}, x_{i j k 3}\right), k=1,2, \ldots, K$, which $\tilde{x}_{i j k}$ represents the value of the $i$ th alternative respect to the $j$ th criterion by $k$ th decision maker. Then the aggregated fuzzy rating can be defined as:

$$
\tilde{x}_{i j}=\left(x_{i j 1}, x_{i j 2}, x_{i j 3}\right), \quad k=1,2, \ldots, K,
$$


where:

$$
\begin{aligned}
& x_{i j 1}=\frac{1}{K} \sum_{k=1}^{k} x_{i j k 1} ; \\
& x_{i j 2}=\frac{1}{K} \sum_{k=1}^{k} x_{i j k 2} ; \\
& x_{i j 3}=\frac{1}{K} \sum_{k=1}^{k} x_{i j k 3} .
\end{aligned}
$$

Step 4. Calculate the normalized fuzzy decision matrix. In order to transform the various criteria scales into a comparable scale, the linear scale transformation is employed that the ranges of normalized TFNs belong to closed interval zero and one. The normalized fuzzy decision matrix can be computed by $\tilde{R}$ :

$$
\tilde{R}=\left[\tilde{r}_{i j}\right]_{m \times n}
$$

and

$$
\begin{aligned}
& \tilde{r}_{i j}=\left(\frac{x_{i j 1}}{x_{j 3}^{*}}, \frac{x_{i j 2}}{x_{j 3}^{*}}, \frac{x_{i j 3}}{x_{j 3}^{*}}\right), x_{j 3}^{*}=\max _{i} x_{i j 3}, \\
& \tilde{r}_{i j}=\left(\frac{x_{j 1}^{*}}{x_{i j 3}}, \frac{x_{j 1}^{*}}{x_{i j 2}}, \frac{x_{j 1}^{*}}{x_{i j 1}}\right), \quad x_{j 1}^{*}=\min _{i} x_{j 1},
\end{aligned}
$$

where $r_{i j}$ is the normalized value of $x_{i j}$.

Step 5. Calculate the weighted normalized fuzzy decision matrix. We can compute the weighted normalized fuzzy decision matrix by considering the relative importance of evaluation criteria as:

$$
\tilde{V}=\left[\tilde{v}_{i j}\right]_{m \times n}
$$

and

$$
\tilde{v}_{i j}=\tilde{r}_{i j} \times \tilde{w}_{j},
$$

where $\tilde{w}_{j}$ is the weights of the criteria that are obtained by FAHP in this paper.

Step 6. Identify positive ideal $\left(\mathrm{A}^{*}\right)$ and negative ideal $\left(\mathrm{A}^{-}\right)$solutions. The fuzzy positive - ideal solution and the fuzzy negative-ideal solution are shown in Eqns (14), (15):

$$
\begin{aligned}
& A^{*}=\left(\tilde{v}_{1}^{+}, \tilde{v}_{2}^{+}, \tilde{v}_{3}^{+}, \ldots, \tilde{v}_{n}^{+}\right)=\left\{\max _{i} v_{i j} \mid(i=1,2, \ldots, n)\right\} ; \\
& A^{-}=\left(\tilde{v}_{1}^{-}, \tilde{v}_{2}^{-}, \tilde{v}_{3}^{-}, \ldots, \tilde{v}_{n}^{-}\right)=\left\{\min _{i} v_{i j} \mid(i=1,2, \ldots, n)\right\} .
\end{aligned}
$$

Step 7. Calculate separation measures. The distance of each alternative from $\mathrm{A}^{*}$ and $\mathrm{A}^{-}$can be currently calculated using Eqns (16), (17):

$$
\begin{aligned}
& d_{i}^{+}=\sum_{j=1}^{n} d\left(\tilde{v}_{i j}, \tilde{v}_{j}^{+}\right), i=1,2, \ldots, m ; \\
& d_{i}^{-}=\sum_{j=1}^{n} d\left(\tilde{v}_{i j}, \tilde{v}_{j}^{-}\right), i=1,2, \ldots, m .
\end{aligned}
$$

Step 8. Calculate the similarities to ideal solution. This step solves the similarities to an ideal solution by Eqn (18):

$$
C C_{i}^{*}=\frac{d_{i}^{-}}{d_{i}^{-}+d_{i}^{*}} .
$$

Step 9. Rank preference order. Choose an alternative with maximum $C C_{i}^{*}$ or rank alternatives according to $C C_{i}^{*}$ in descending order.

\section{The proposed model}

The proposed model for selecting the best handling equipment, integrated of FAHP and FTOPSIS techniques under group decision making, includes three main steps: (1) determine the evaluation criteria in the decision making process; (2) calculate the importance weights of the evaluation criteria by Buckley's FAHP; (3) measure the preference ratings of alternatives with FTOPSIS method and select the alternative with the highest score as the first choice. In the first step, alternatives and evaluation criteria are determined and the structure of hierarchy is constructed. In the second step, the importance weights of evaluation criteria are obtained by decision maker team in the template of FAHP questionnaire. The decision maker team contains of ten experts with high degree of knowledge in the field of mine design. In this step, the weights of criteria are calculated by pairwise comparison matrixes formed by decision maker team based on the scale given in Table 1. As shown in Table 1, linguistic values and the membership functions of these linguistic values are listed for evaluation of criteria. The values obtained from individual evaluations are converted into final pairwise comparison matrix by the arithmetic mean to find a consensus on weight of criteria.

In the last step, alternatives are ranked in descending order using FTOPSIS method. In the first phase of this step, experts with the help of scale given in Table 2 and Figure 2 determine the rating of alternatives with respect to each criterion. After forming decision making matrix, the computations of the FTOPSIS method for evaluating the existing alternatives with respect to the evaluation criteria under consideration is implemented. In the last phase of this step, final ranking of alternatives in descending order is obtained and the optimal handling equipment is chosen. Schematic diagram of the proposed model for handling equipment selection is depicted in Figure 3.

\section{An illustrative example}

The proposed model is applied to select the most appropriate handling equipment in an open pit mine. The Sangan mine is one of the largest iron deposits of Iran which is situated $308 \mathrm{~km}$ southeast of Mashhad city in the northeast of the country (Fig. 4). This mine is designed to have an initial annual production of $3.4 \mathrm{Mt}$ iron ore concentrate (Monjezi et al. 2011). The deposit of this mine comprises of a magnetite skarn and it is known as iron-oxidetype deposit. The case is implemented by using a step-bystep procedure as follows: 
Step 1. After reviewing the literatures and a lot of face-to-face interviews, solid information is developed on the evaluation criteria and alternatives. After preliminary screening, three alternatives have left in the list of feasible alternatives, including belt conveyor system (A1), truck (A2), and truck-in-pit crusher-belt conveyor system (A3). Some basic features of these three systems are listed in Table 3. Then, a group of decision makers contains of ten experts with minimum four years' experience in the field of mining design in an assembly process identified the effective criteria as Capital cost (C1), Operation cost (C2), Production (C3), Material size (C4), Ground condition (C5), Distance (C6), Weather condition (C7), Environment (C8), Risk (C9), Reliability (C10), Efficiency (C11), Availability (C12), Safety (C13), Flexibility (C14), and Useful life (C15). These fifteen criteria are classified into three main criteria, including Economic parameters (EP), Operating parameters (OP), and Technical parameters (TP).

Among the effective criteria, the first two criteria and the ninth criterion (i.e. C1, C2, and C9) are the cost type criteria (the lower, the better). The rest of the evaluation criteria (i.e. C3, C4, C5, C6, C7, C8, C10, C11, C12, $\mathrm{C} 13, \mathrm{C} 14$, and $\mathrm{C} 15$ ) are the benefit type criteria (the higher, the better).

The hierarchy of handling equipment selection presented in Figure 5 can be divided into four levels: level 1 includes the goal of the decision hierarchy, which is selection the optimum handling equipment. The criteria are on the second level. The sub-criteria are located in the third level. Level 4 comprises the decision alternatives.

Step 2. After constructing the decision hierarchy, the importance weights of the criteria are obtained by using the computations of the FAHP method. For achieving the aim, the ten evaluators are asked to form individual pairwise comparison matrix based on the scale given in Table 1. For example, when comparing the Reliability and Efficiency, the responses of ten evaluators are EI, EI, EI, IMI, EI, IMI, (IMI)*, EI, MI, and EI, respectively.

\footnotetext{
Triangular fuzzy reciprocal scale
}

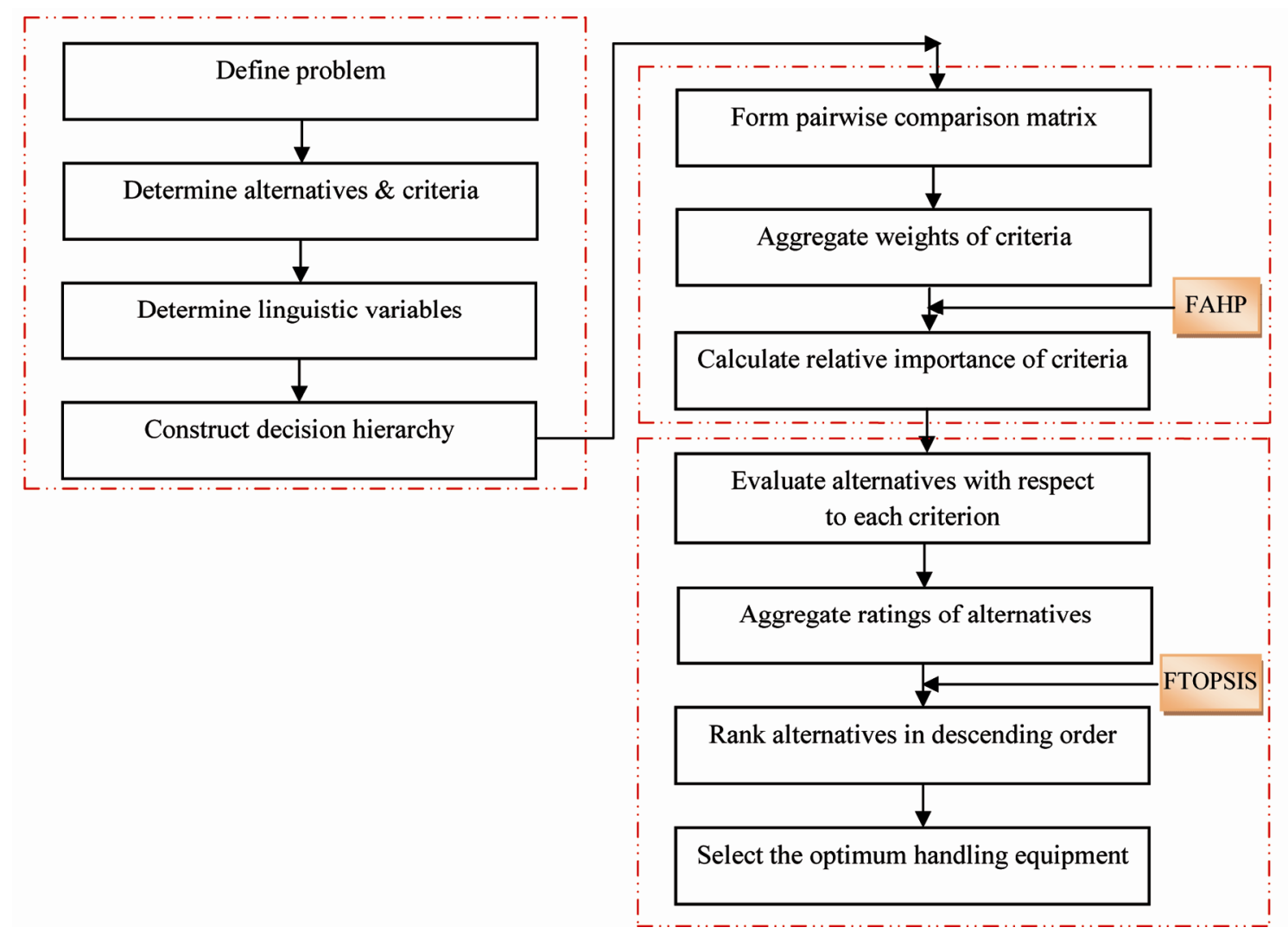

Fig. 3. Schematic diagram of the proposed model

Table 3. Some basic features of alternatives

\begin{tabular}{lccc}
\hline & A1 & A2 & A3 \\
\hline Capital cast (\$) & 2904100 & 2340000 & 2736000 \\
Operation Cost (\$) & 208.66 & 194.62 & 187.85 \\
Useful life (year) & 18 & 14 & 10 \\
\hline
\end{tabular}




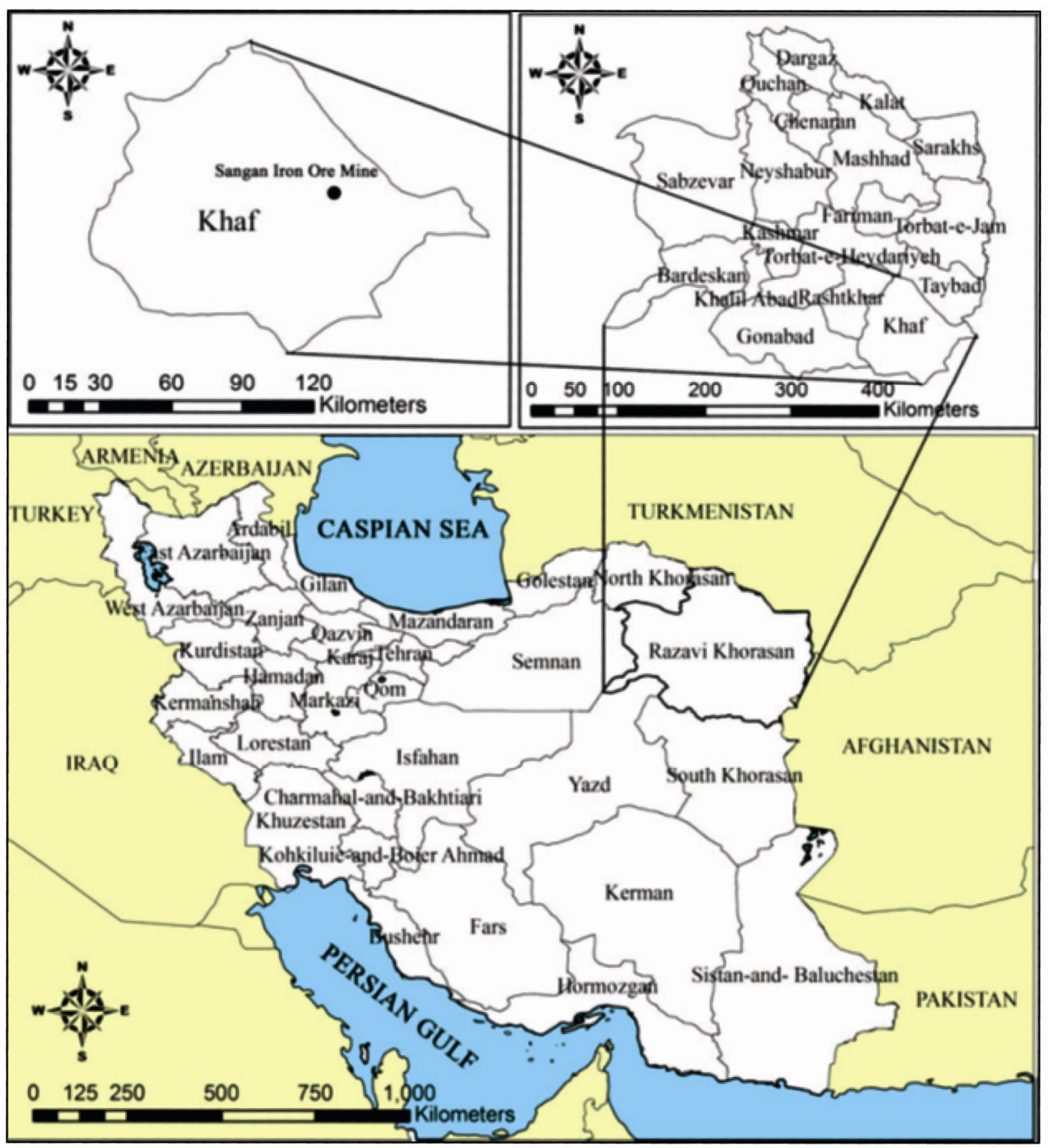

Fig. 4. Geography of Sangan iron mine (Naghizadeh et al. 2011)

The responses gathered from ten questionnaires filled by the experts are transferred into a final pairwise comparison matrix to the results be aggregated. In this paper, Buckley's FAHP methodology that applies the geometric mean technique is used for calculating the elements of the synthetic pairwise comparison matrix in order to obtain a consensus as presented in Table 4.

As a sample, $\tilde{a}_{C 10 C 11}$ is calculated as follows:

$\tilde{a}_{C 10 . C 11}=((1,1,1) \otimes(1,1,1) \otimes(1,1,1) \otimes(1,2,3) \otimes(1,1,1) \otimes$

$(1,2,3) \otimes(1 / 3,1 / 2,1) \otimes(1,1,1) \otimes(1,2,3) \otimes(1,1,1))^{1 / 10}=$

$\left((1 \times 1 \times 1 \times 1 \times 1 \times 1 \times 1 / 3 \times 1 \times 1 \times 1)^{1 / 10}\right.$,

$(1 \times 1 \times 1 \times 2 \times 1 \times 2 \times 1 / 2 \times 1 \times 2 \times 1)^{1 / 10}$,

$\left.(1 \times 1 \times 1 \times 3 \times 1 \times 3 \times 1 \times 1 \times 3 \times 1)^{1 / 10}\right)=$

$(0.896,1.149,1.39)$.

Similar calculations were carried out for the other elements and the results are listed in Table 4.

The fuzzy weights of the main and sub-criteria are computed by Eqn (5), the computations are presented as follows:

$$
\begin{aligned}
& \tilde{r}_{E P}=\left((1 \times 0.77 \times 1.23)^{1 / 3},(1 \times 0.96 \times 2.29)^{1 / 3},\right. \\
& \left.(1 \times 1.29 \times \cdots \times 3.37)^{1 / 3}\right)=(0.98,1.3,1.63) .
\end{aligned}
$$

Similar calculations are conducted for the other main and sub-criteria and the results are summarized in the following part:

$$
\begin{aligned}
& \tilde{r}_{O P}=(0.95,1.31,1.61), \tilde{r}_{T P}=(0.45,0.59,0.9), \\
& \tilde{r}_{1}=(0.6,0.84,1.08), \tilde{r}_{2}=(0.93,1.19,1.66), \\
& \tilde{r}_{3}=(1.55,2.25,2.83), \\
& \tilde{r}_{4}=(0.46,0.66,0.96), \tilde{r}_{5}=(0.79,1.15,1.75), \\
& \tilde{r}_{6}=(1.62,2.23,2.94), \tilde{r}_{7}=(0.31,0.39,0.57), \\
& \tilde{r}_{8}=(0.45,0.66,0.96), \\
& \tilde{r}_{9}=(0.68,1.01,1.57), \tilde{r}_{10}=(1.37,1.9,2.52), \\
& \tilde{r}_{11}=(1.04,1.6,2.1), \tilde{r}_{12}=(0.55,0.79,1.15), \\
& \tilde{r}_{13}=(1.33,1.73,2.36), \\
& \tilde{r}_{14}=(0.28,0.36,0.5), \tilde{r}_{15}=(0.5,0.68,0.96) .
\end{aligned}
$$

The weight of each criterion can be calculated through Eqn (6): 
$\tilde{w}_{E P}=(0.98,1.3,1.63) \otimes(1 /(1.63+1.61+0.9)$,

$1 /(1.3+1.31+0.59), 1 /(0.98+0.95+0.45))=$

$(0.24,0.41,0.68)$

Similarly, the remaining $\tilde{w}_{i}$ are obtained as follows:

$$
\begin{aligned}
& \tilde{w}_{O P}=(0.23,0.41,0.68), \tilde{w}_{T P}=(0.11,0.18,0.38), \\
& \tilde{w}_{1}=(0.22,0.41,0.7), \tilde{w}_{2}=(0.34,0.59,1.09), \\
& \tilde{w}_{3}=(0.13,0.27,0.48), \tilde{w}_{4}=(0.04,0.08,0.16), \\
& \tilde{w}_{5}=(0.07,0.14,0.3), \tilde{w}_{6}=(0.14,0.27,0.5), \\
& \tilde{w}_{7}=(0.03,0.05,0.1), \tilde{w}_{8}=(0.04,0.08,0.16), \\
& \tilde{w}_{9}=(0.06,0.12,0.27), \tilde{w}_{10}=(0.14,0.27,0.5), \\
& \tilde{w}_{11}=(0.11,0.23,0.41), \tilde{w}_{12}=(0.06,0.11,0.23), \\
& \tilde{w}_{13}=(0.14,0.26,0.47), \tilde{w}_{14}=(0.03,0.05,0.1), \\
& \tilde{w}_{15}=(0.05,0.1,0.19) .
\end{aligned}
$$

The output of fuzzy synthetic decisions obtained by each dimension is a fuzzy number. Therefore, it is necessary to convert fuzzy numbers into crisp numbers by defuzzification in order to compare the relative importance of dimensions. The procedure of defuzzification is to locate the Best Nonfuzzy Performance (BNP) value. Methods of such defuzzified fuzzy ranking generally include mean of maximal (MOM), center of area (COA), and $\alpha$-cut (Chen et al. 2011).
This research for transforming the fuzzy weights into the crisp weights applies the centre of area (COA) method which is a simple and practical method (Fouladgar et al. 2012a) to compute the best nonfuzzy performance (BNP) value of the fuzzy weights of each criterion. The BNP value of the fuzzy number $\tilde{R}_{i}$ can be found by using Eqn (19):

$$
B N P_{i}=\frac{\left[\left(U R_{i}-L R_{i}\right)+\left(M R_{i}-L R_{i}\right)\right]}{3}+L R_{i} .
$$

The relative weights of the main and sub-criteria and their ranks are shown in Table 5 .

As seen in Table 5, the relative weights for the evaluation criterion are: Operation cost (0.355), Capital cost (0.234), Distance (0.161), Production (0.156), Ground condition (0.092), Reliability (0.084), Risk (0.081), Safety (0.079), Efficiency (0.07), Material size (0.051), Environment (0.051), Availability (0.037), Useful life (0.032), Weather condition (0.03), and Flexibility (0.017). Based on the weights obtained by FAHP, the most important criteria for the evaluation of handling equipment is Oper-

\begin{tabular}{|c|c|c|c|c|c|c|c|c|c|c|c|c|c|c|c|c|c|c|c|c|c|}
\hline & \multicolumn{3}{|c|}{ C3 } & \multicolumn{3}{|c|}{$\mathrm{C} 4$} & \multicolumn{3}{|c|}{ C5 } & \multicolumn{3}{|c|}{ C6 } & \multicolumn{3}{|c|}{ C7 } & \multicolumn{3}{|c|}{ C8 } & \multicolumn{3}{|c|}{ C9 } \\
\hline C3 & 1.00 & 1.00 & 1.00 & 2.43 & 3.56 & 4.71 & 1.32 & 2.47 & 3.57 & 0.69 & 0.92 & 1.16 & 3.24 & 4.35 & 4.51 & 2.65 & 3.72 & 4.87 & 1.12 & 2.23 & 3.39 \\
\hline $\mathrm{C} 4$ & 0.21 & 0.28 & 0.41 & 1.00 & 1.00 & 1.00 & 0.37 & 0.54 & 0.79 & 0.24 & 0.34 & 0.47 & 0.96 & 1.76 & 2.83 & 0.66 & 1.12 & 1.92 & 0.34 & 0.56 & 0.92 \\
\hline $\mathrm{C} 5$ & 0.28 & 0.40 & 0.76 & 1.27 & 1.85 & 2.70 & 1.00 & 1.00 & 1.00 & 0.34 & 0.53 & 0.87 & 2.21 & 3.27 & 4.38 & 0.92 & 1.73 & 2.84 & 0.78 & 1.21 & 2.28 \\
\hline C6 & 0.86 & 1.09 & 1.45 & 2.13 & 2.94 & 4.17 & 1.15 & 1.89 & 2.94 & 1.00 & 1.00 & 1.00 & 3.24 & 4.36 & 5.54 & 3.12 & 4.19 & 5.31 & 1.39 & 2.46 & 3.67 \\
\hline C7 & 0.22 & 0.23 & 0.31 & 0.35 & 0.57 & 1.04 & 0.23 & 0.31 & 0.45 & 0.18 & 0.23 & 0.31 & 1.00 & 1.00 & 1.00 & 0.31 & 0.48 & 0.82 & 0.25 & 0.34 & 0.51 \\
\hline $\mathrm{C} 8$ & 0.21 & 0.27 & 0.38 & 0.52 & 0.89 & 1.52 & 0.35 & 0.58 & 1.09 & 0.19 & 0.24 & 0.32 & 1.22 & 2.08 & 3.23 & 1.00 & 1.00 & 1.00 & 0.42 & 0.76 & 1.14 \\
\hline C9 & 0.29 & 0.45 & 0.89 & 1.09 & 1.79 & 2.94 & 0.44 & 0.83 & 1.28 & 0.27 & 0.41 & 0.72 & 1.96 & 2.94 & 4.00 & 0.88 & 1.32 & 2.38 & 1.00 & 1.00 & 1.00 \\
\hline
\end{tabular}
ation cost (0.355). Moreover, the less important criterion is Flexibility $(0.017)$. The ranks of the evaluation criteria from the largest to smallest are schematically shown in Figure 6.

Table 4. Synthetic pairwise comparison matrices

\begin{tabular}{llllllllll}
\hline & & EP & & & OP & & TP \\
\hline EP & 1.00 & 1.00 & 1.00 & 0.77 & 0.96 & 1.29 & 1.23 & 2.29 & 3.37 \\
OP & 0.78 & 1.04 & 1.30 & 1.00 & 1.00 & 1.00 & 1.12 & 2.16 & 3.24 \\
TP & 0.30 & 0.44 & 0.81 & 0.31 & 0.46 & 0.89 & 1.00 & 1.00 & 1.00 \\
\hline
\end{tabular}

Table 4. Continued

\begin{tabular}{lllllll}
\hline & & $\mathrm{C} 1$ & & $\mathrm{C} 2$ & \\
\hline $\mathrm{C} 1$ & 1.00 & 1.00 & 1.00 & 0.36 & 0.71 & 1.16 \\
$\mathrm{C} 2$ & 0.86 & 1.41 & 2.78 & 1.00 & 1.00 & 1.00 \\
\hline
\end{tabular}

Table 4. Continued

Table 4. Continued

\begin{tabular}{llllllllllllllllllll}
\hline & & $\mathrm{C} 10$ & & & $\mathrm{C} 11$ & & & $\mathrm{C} 12$ & & & $\mathrm{C} 13$ & & & $\mathrm{C} 14$ & \\
$\mathrm{C} 10$ & 1.00 & 1.00 & 1.00 & 0.87 & 1.12 & 2.15 & 1.46 & 2.52 & 3.67 & 0.57 & 0.96 & 1.16 & 4.08 & 5.15 & 6.31 & 2.23 & 3.33 & 4.47 \\
$\mathrm{C} 11$ & 0.47 & 0.89 & 1.15 & 1.00 & 1.00 & 1.00 & 1.31 & 2.42 & 3.57 & 0.62 & 0.87 & 1.23 & 2.96 & 4.12 & 5.15 & 1.12 & 2.19 & 3.27 \\
$\mathrm{C} 12$ & 0.27 & 0.40 & 0.68 & 0.28 & 0.41 & 0.76 & 1.00 & 1.00 & 1.00 & 0.38 & 0.63 & 0.94 & 1.23 & 2.34 & 3.47 & 0.76 & 0.98 & 1.35 \\
$\mathrm{C} 13$ & 0.86 & 1.04 & 1.75 & 0.81 & 1.15 & 1.61 & 1.06 & 1.59 & 2.63 & 1.00 & 1.00 & 1.00 & 3.14 & 4.21 & 5.22 & 2.32 & 3.39 & 4.47 \\
$\mathrm{C} 14$ & 0.16 & 0.19 & 0.25 & 0.19 & 0.24 & 0.34 & 0.29 & 0.43 & 0.81 & 0.19 & 0.24 & 0.32 & 1.00 & 1.00 & 1.00 & 0.29 & 0.42 & 0.76 \\
$\mathrm{C} 15$ & 0.22 & 0.30 & 0.45 & 0.31 & 0.46 & 0.89 & 0.74 & 1.02 & 1.32 & 0.22 & 0.29 & 0.43 & 1.32 & 2.38 & 3.45 & 1.00 & 1.00 & 1.00 \\
\hline
\end{tabular}


Table 5. Relative weight of the evaluation criteria

\begin{tabular}{|c|c|c|c|c|}
\hline Main and sub-criteria & Local weights & Global weights & BNP & Rank \\
\hline Economic parameters & $(0.24,0.41,0.68)$ & - & - & \\
\hline Capital cost & $(0.22,0.42,0.70)$ & $(0.052,0.169,0.482)$ & 0.234 & 2 \\
\hline Operation cost & $(0.34,0.58,1.09)$ & $(0.080,0.238,0.746)$ & 0.355 & 1 \\
\hline Operating parameters & $(0.23,0.41,0.68)$ & - & - & \\
\hline Production & $(0.13,0.27,0.48)$ & $(0.031,0.110,0.327)$ & 0.156 & 4 \\
\hline Material size & $(0.04,0.08,0.16)$ & $(0.009,0.033,0.111)$ & 0.051 & 10 \\
\hline Ground condition & $(0.07,0.14,0.30)$ & $(0.016,0.057,0.203)$ & 0.092 & 5 \\
\hline Distance & $(0.14,0.27,0.50)$ & $(0.032,0.109,0.341)$ & 0.161 & 3 \\
\hline Weather condition & $(0.03,0.05,0.10)$ & $(0.006,0.019,0.066)$ & 0.030 & 14 \\
\hline Environment & $(0.04,0.08,0.16)$ & $(0.009,0.032,0.111)$ & 0.051 & 11 \\
\hline Risk & $(0.06,0.12,0.27)$ & $(0.013,0.049,0.181)$ & 0.081 & 7 \\
\hline Technical parameters & $(0.11,0.18,0.38)$ & - & - & \\
\hline Reliability & $(0.14,0.27,0.50)$ & $(0.016,0.049,0.188)$ & 0.084 & 6 \\
\hline Efficiency & $(0.11,0.23,0.41)$ & $(0.012,0.042,0.156)$ & 0.070 & 9 \\
\hline Availability & $(0.06,0.11,0.23)$ & $(0.006,0.020,0.086)$ & 0.037 & 12 \\
\hline Safety & $(0.14,0.25,0.47)$ & $(0.015,0.045,0.176)$ & 0.079 & 8 \\
\hline Flexibility & $(0.03,0.05,0.10)$ & $(0.003,0.009,0.037)$ & 0.017 & 15 \\
\hline Useful life & $(0.05,0.10,0.19)$ & $(0.006,0.018,0.071)$ & 0.032 & 13 \\
\hline
\end{tabular}

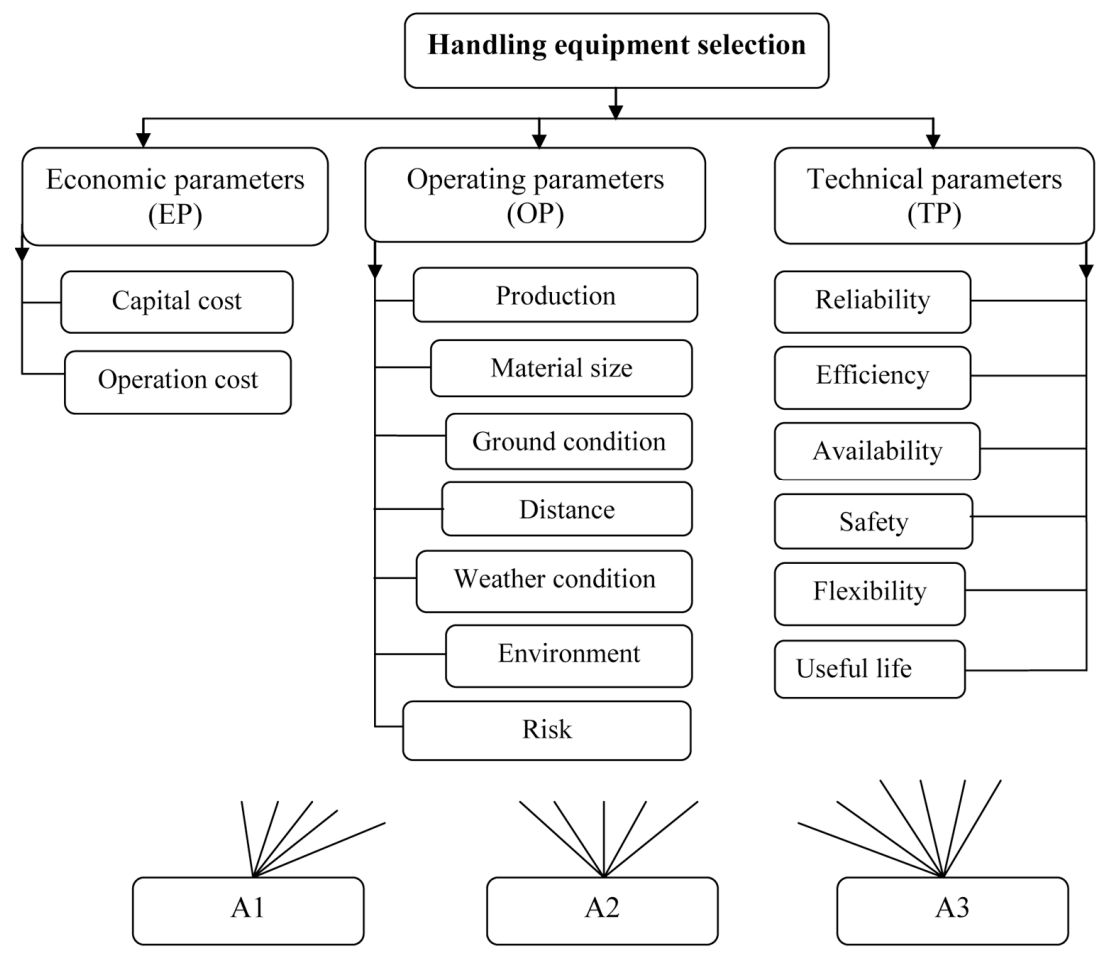

Fig. 5. Decision hierarchy

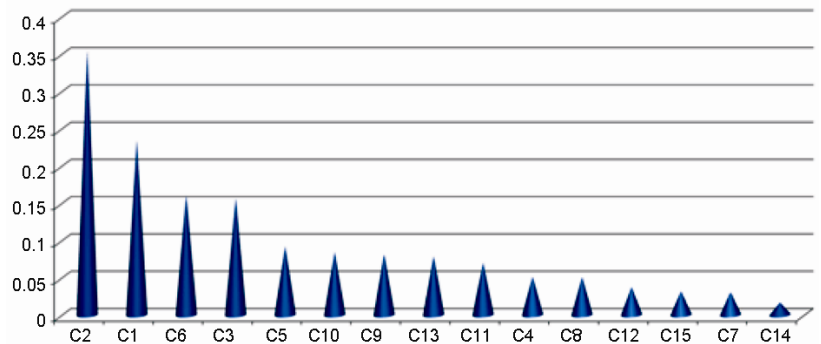

Fig. 6. Ranking of criteria
Step 3. In the last step, fuzzy evaluation matrices are established by ten evaluators for evaluating the handling equipment methods with respect to the criteria under consideration based on linguistic variables given in Table 2 and Figure 2. For example, the fuzzy decision matrix filled by one of the experts is shown in Table 6 .

Then, the aggregated fuzzy performance ratings of handling methods with respect to each criterion are calculated by Eqn (9) and the results are presented in Table 7.

The second phase of this step is to normalize the aggregated fuzzy decision matrix using Eqn (11). After normalizing the decision matrix, by applying the relative importance of the evaluation criteria derived in previous step, the weighted decision matrix is resulted as shown in Table 8. 
Table 6. A sample of filled questionnaire

\begin{tabular}{cccc}
\hline & A1 & A2 & A3 \\
\hline C3 & VG & G & VG \\
C4 & VP & VG & G \\
C5 & VP & G & G \\
C6 & G & G & VG \\
C7 & VP & G & P \\
C8 & G & F & G \\
C9 & VG & P & G \\
C10 & F & G & G \\
C11 & G & F & VG \\
C12 & G & VG & P \\
C13 & G & F & F \\
C14 & VP & VG & F \\
\hline
\end{tabular}

Then, the fuzzy positive ideal solution (FPIS, $A^{+}$) and the fuzzy negative ideal solutions (FNIS, $A^{-}$) are calculated. Fuzzy preferences are normalized positive triangular fuzzy numbers, so the FPIS and the FNIS can be defined as $\tilde{v}_{i}^{+}=w_{j} \otimes(1,1,1)$ and $\tilde{v}_{i}^{-}=(0,0,0)$. The distance of each alternative from $A^{+}$and $A^{-}$is calculated by using Eqns (16) and (17).
In the last phase of this step, the alternatives are ranked in descending order as listed in Table 9. According to $\mathrm{CC}_{\mathrm{i}}$ values, the final ranking of the alternatives in descending order are $\mathrm{A} 2, \mathrm{~A} 3$, and $\mathrm{A} 1$. The proposed model shows that Truck (A2) is the most appropriate handling system with $\mathrm{CC}$ value of 0.642 . Final rankings of the handling equipment based on $\mathrm{CC}_{\mathrm{i}}$ values are depicted in Figure 7.

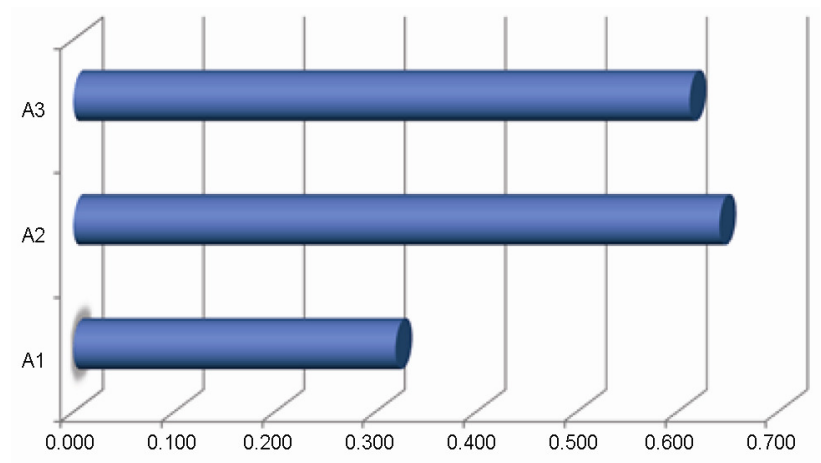

Fig. 7. Final rankings of alternatives

Table 7. Aggregated fuzzy performance ratings

\begin{tabular}{cccccccccc}
\hline & A1 & \multicolumn{3}{c}{ A2 } & & & A3 \\
\hline C1 & 2904100 & 2904100 & 2904100 & 2340000 & 2340000 & 2340000 & 2736000 & 2736000 & 2736000 \\
C2 & 209 & 209 & 209 & 195 & 195 & 195 & 188 & 188 & 188 \\
C3 & 5 & 7.43 & 10.00 & 3 & 6.53 & 9 & 5 & 7.23 & 10 \\
C4 & 0 & 2.07 & 5.00 & 5 & 7.76 & 10 & 3 & 6.42 & 9 \\
C5 & 0 & 2.12 & 5.00 & 3 & 6.59 & 9 & 3 & 6.89 & 10 \\
C6 & 3 & 6.24 & 9.00 & 3 & 6.74 & 10 & 5 & 7.32 & 10 \\
C7 & 0 & 1.87 & 5.00 & 3 & 6.34 & 9 & 0 & 3.17 & 7 \\
C8 & 3 & 6.54 & 9.00 & 1 & 4.46 & 9 & 3 & 6.32 & 9 \\
C9 & 5 & 7.87 & 10.00 & 1 & 3.12 & 7 & 3 & 6.94 & 10 \\
C10 & 1 & 4.31 & 7.00 & 3 & 6.43 & 9 & 3 & 6.57 & 9 \\
C11 & 3 & 6.45 & 9.00 & 1 & 4.57 & 7 & 5 & 7.12 & 10 \\
C12 & 3 & 6.92 & 10.00 & 5 & 7.56 & 10 & 1 & 3.24 & 7 \\
C13 & 1 & 6.21 & 9.00 & 1 & 4.23 & 7 & 1 & 4.36 & 7 \\
C14 & 0 & 3.12 & 7.00 & 5 & 7.21 & 10 & 1 & 4.67 & 10 \\
C15 & 18 & 18.00 & 18.00 & 14 & 14 & 14 & 10 & 10 \\
\hline
\end{tabular}

Table 8. Weighted decision matrix

\begin{tabular}{llllllllll}
\hline & \multicolumn{3}{c}{ A1 } & & & A2 & & & A3 \\
\hline C1 & 0.00 & 0.00 & 0.00 & 0.15 & 0.15 & 0.15 & 0.05 & 0.05 & 0.05 \\
C2 & 0.00 & 0.00 & 0.00 & 0.16 & 0.16 & 0.16 & 0.23 & 0.23 & 0.23 \\
C3 & 0.03 & 0.06 & 0.10 & 0.00 & 0.05 & 0.09 & 0.03 & 0.06 & 0.10 \\
C4 & 0.00 & 0.01 & 0.02 & 0.02 & 0.03 & 0.03 & 0.01 & 0.02 & 0.03 \\
C5 & 0.00 & 0.01 & 0.03 & 0.02 & 0.04 & 0.05 & 0.02 & 0.04 & 0.06 \\
C6 & 0.00 & 0.05 & 0.09 & 0.00 & 0.06 & 0.11 & 0.03 & 0.06 & 0.11 \\
C7 & 0.00 & 0.00 & 0.01 & 0.01 & 0.01 & 0.02 & 0.00 & 0.01 & 0.02 \\
C8 & 0.01 & 0.02 & 0.03 & 0.00 & 0.01 & 0.03 & 0.01 & 0.02 & 0.03 \\
C9 & 0.03 & 0.01 & 0.00 & 0.05 & 0.04 & 0.02 & 0.04 & 0.02 & 0.00 \\
C10 & 0.00 & 0.02 & 0.04 & 0.01 & 0.04 & 0.06 & 0.01 & 0.04 & 0.06 \\
C11 & 0.01 & 0.03 & 0.04 & 0.00 & 0.02 & 0.03 & 0.02 & 0.03 & 0.05 \\
C12 & 0.01 & 0.02 & 0.02 & 0.01 & 0.02 & 0.02 & 0.00 & 0.01 & 0.02 \\
C13 & 0.00 & 0.03 & 0.05 & 0.00 & 0.02 & 0.04 & 0.00 & 0.02 & 0.04 \\
C14 & 0.00 & 0.00 & 0.01 & 0.01 & 0.01 & 0.01 & 0.00 & 0.01 & 0.01 \\
C15 & 0.02 & 0.02 & 0.02 & 0.01 & 0.01 & 0.01 & 0.00 & 0.00 & 0.00 \\
\hline
\end{tabular}


Table 9. FTOPSIS results

\begin{tabular}{ccccc}
\hline Alternatives & $D_{j}^{+}$ & $D_{j}^{-}$ & $C C_{j}$ & Rank \\
\hline A1 & 0.730 & 0.344 & 0.32 & 3 \\
A2 & 0.391 & 0.701 & 0.642 & 1 \\
A3 & 0.419 & 0.662 & 0.612 & 2 \\
\hline
\end{tabular}

\section{Sensitivity analysis}

In order to identify the cause of the difference in the outcome of the proposed model, a sensitivity analysis is conducted. This technique generates different scenarios that may change the priority of alternatives and be needed to reach a consensus. If the ranking order is changed by increasing or decreasing the importance of the criteria, the results are expressed to be sensitive otherwise it is robust (Yazdani-Chamzini, Yakhchali 2012). In this study, sensitivity analysis is conducted to see how sensitive the alternatives change with the importance of the criteria. This tool graphical exposes the importance of criteria weights in selecting the optimal alternative among the feasible alternatives. The main goal of sensitivity analysis is to see which criteria is most significant in influencing the decision making process. For this reason, thirty experiments were conducted that each experiment is generated by an increase of $300 \%$ and $400 \%$ in the amount of the weight of the criterion under consideration. Table 10 presents the details of these experiments.

It can be shown from Figure 8 that out of thirty experiments, alternative A2 has the highest score in twenty six experiments. In the rest of the experiments (experiment numbers $2,17,18$, and 26), alternative $\mathrm{A} 3$ is located in the top level as the winner. Therefore, it can be resulted that the decision making process is rarely sensitive to the criteria weight with alternative A2 emerging as the winner ( $87 \%$ votes).

\section{Conclusion}

The problem of handling equipment selection plays a critical role in the process of mining design because it takes a great deal of the overall costs. For this reason, designers and managers should employ an efficient and capable method to select the most appropriate handling system among a pool of alternatives. The handling equipment selection problem is often influenced by uncertainty in real world, and in such circumstances fuzzy set theory is an appropriate tool to face with this type of problems and handle the existing uncertainty. In practice, it is difficult or even impossible for decision makers to express the precise numerical information on the weights and the ratings; for this reason, the linguistic terms are useful. Likewise, by applying group decision making

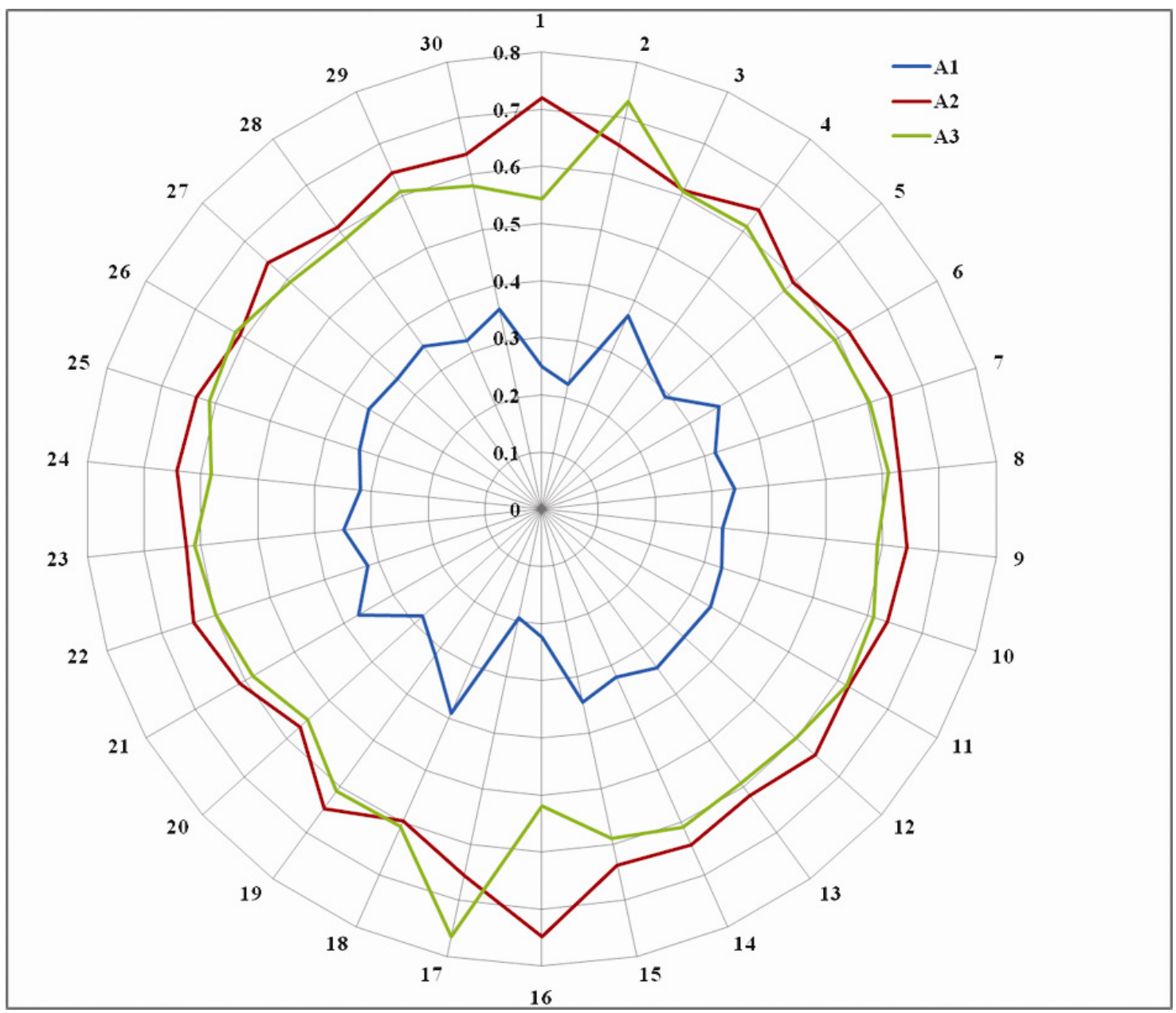

Fig. 8. Sensitivity analysis 
Table 10. Changing the criteria weights for sensitivity analysis

\begin{tabular}{|c|c|c|c|c|c|}
\hline No. & Weights of criteria & Ranking & No. & Weights of criteria & Ranking \\
\hline 1 & $W_{C l(\text { new })}=3 \times W_{C l(\text { old })}$ & $\mathrm{A} 2>\mathrm{A} 3>\mathrm{A} 1$ & 16 & $W_{C l(\text { new })}=4 \times W_{C l(\text { old })}$ & $\mathrm{A} 2>\mathrm{A} 3>\mathrm{A} 1$ \\
\hline 2 & $W_{C 2(\text { new })}=3 \times W_{C 2(\text { old })}$ & $\mathrm{A} 3>\mathrm{A} 2>\mathrm{A} 1$ & 17 & $W_{C 2(\text { new })}=4 \times W_{C 2(\text { old })}$ & $\mathrm{A} 3>\mathrm{A} 2>\mathrm{A} 1$ \\
\hline 3 & $W_{C 3(\text { new })}=3 \times W_{C 3(\text { old })}$ & $\mathrm{A} 2>\mathrm{A} 3>\mathrm{A} 1$ & 18 & $W_{C 3(\text { new })}=4 \times W_{C 3(\text { old })}$ & $\mathrm{A} 3>\mathrm{A} 2>\mathrm{A} 1$ \\
\hline 4 & $W_{C 4(\text { new })}=3 \times W_{C 4(\text { old })}$ & $\mathrm{A} 2>\mathrm{A} 3>\mathrm{A} 1$ & 19 & $W_{C 4(\text { new })}=4 \times W_{C 4(\text { old })}$ & $\mathrm{A} 2>\mathrm{A} 3>\mathrm{A} 1$ \\
\hline 5 & $W_{C 5(\text { new })}=3 \times W_{C 5(\text { old })}$ & $\mathrm{A} 2>\mathrm{A} 3>\mathrm{A} 1$ & 20 & $W_{C 5(\text { new })}=4 \times W_{C 5(\text { old })}$ & $\mathrm{A} 2>\mathrm{A} 3>\mathrm{A} 1$ \\
\hline 6 & $W_{C 6(n e w)}=3 \times W_{C 6(\text { old })}$ & $\mathrm{A} 2>\mathrm{A} 3>\mathrm{A} 1$ & 21 & $W_{C 6(\text { new })}=4 \times W_{C 6(\text { old })}$ & $\mathrm{A} 2>\mathrm{A} 3>\mathrm{A} 1$ \\
\hline 7 & $W_{C 7(\text { new })}=3 \times W_{C 7(\text { old })}$ & $\mathrm{A} 2>\mathrm{A} 3>\mathrm{A} 1$ & 22 & $W_{C 7(\text { new })}=4 \times W_{C 7(\text { old })}$ & $\mathrm{A} 2>\mathrm{A} 3>\mathrm{A} 1$ \\
\hline 8 & $W_{C 8(\text { new })}=3 \times W_{C 8(\text { old })}$ & $\mathrm{A} 2>\mathrm{A} 3>\mathrm{A} 1$ & 23 & $W_{C 8(\text { new })}=4 \times W_{C 8(\text { old })}$ & $\mathrm{A} 2>\mathrm{A} 3>\mathrm{A} 1$ \\
\hline 9 & $W_{C 9(\text { new })}=3 \times W_{C 9(\text { old })}$ & $\mathrm{A} 2>\mathrm{A} 3>\mathrm{A} 1$ & 24 & $W_{C 9(\text { new })}=4 \times W_{C 9(\text { old })}$ & $\mathrm{A} 2>\mathrm{A} 3>\mathrm{A} 1$ \\
\hline 10 & $W_{C 10(\text { new })}=3 \times W_{C 10(\text { old })}$ & $\mathrm{A} 2>\mathrm{A} 3>\mathrm{A} 1$ & 25 & $W_{C 10(\text { new })}=4 \times W_{C 10(\text { old })}$ & $\mathrm{A} 2>\mathrm{A} 3>\mathrm{A} 1$ \\
\hline 11 & $W_{C 11(\text { new })}=3 \times W_{C 11(\text { old })}$ & $\mathrm{A} 2>\mathrm{A} 3>\mathrm{A} 1$ & 26 & $W_{C 11(\text { new })}=4 \times W_{C 11(\text { old })}$ & $\mathrm{A} 3>\mathrm{A} 2>\mathrm{A} 1$ \\
\hline 12 & $W_{C 12(\text { new })}=3 \times W_{C 12(\text { old })}$ & $\mathrm{A} 2>\mathrm{A} 3>\mathrm{A} 1$ & 27 & $W_{C 12(\text { new })}=4 \times W_{C 12(\text { old })}$ & $\mathrm{A} 2>\mathrm{A} 3>\mathrm{A} 1$ \\
\hline 13 & $W_{C 13(\text { new })}=3 \times W_{C 13(\text { old })}$ & $\mathrm{A} 2>\mathrm{A} 3>\mathrm{A} 1$ & 28 & $W_{C 13(\text { new })}=4 \times W_{C 13 \text { (old })}$ & $\mathrm{A} 2>\mathrm{A} 3>\mathrm{A} 1$ \\
\hline 14 & $W_{C 14(\text { new })}=3 \times W_{C 14(\text { old })}$ & $\mathrm{A} 2>\mathrm{A} 3>\mathrm{A} 1$ & 29 & $W_{C 14(\text { new })}=4 \times W_{C 14(\text { old })}$ & $\mathrm{A} 2>\mathrm{A} 3>\mathrm{A} 1$ \\
\hline 15 & $W_{C 15(\text { new })}=3 \times W_{C 15(\text { old })}$ & $\mathrm{A} 2>\mathrm{A} 3>\mathrm{A} 1$ & 30 & $W_{C 15(\text { new })}=4 \times W_{C 15 \text { (old })}$ & $\mathrm{A} 2>\mathrm{A} 3>\mathrm{A} 1$ \\
\hline
\end{tabular}

(social choice), decision making will be more accurate because it can improve the results by reducing the effect of individual errors.

In this paper, an integrated group model based on FAHP and FTOPSIS is proposed that is able to consider both tangible and intangible criteria for evaluating the feasible alternatives in order to select the best handing equipment. FAHP is used to calculate the weights of the evaluation criteria, while FTOPSIS is utilized to prioritize alternatives. The weights obtained by FAHP are involved in the problem of the handling equipment selection by using them in FTOPSIS computations and ranking order is assigned based on these weights. Finally, the alternative with the highest score is selected. Also, sensitivity analysis was conducted to investigate the influence of criteria weights on the problem of the handling equipment selection. A real world case study is illustrated to show the potential application of the proposed model. However, the proposed method can be applied for tackling MCDM problems in real issues, such as management and engineering problems when information are incomplete, inaccurate, and uncertain by nature.

\section{References}

Anand, G.; Kodali, R.; Kumar, B. S. 2011. Development of analytic network process for the selection of material handling systems in the design of flexible manufacturing systems (FMS), Journal of Advances in Management Research 8(1): 123-147. http://dx.doi.org/10.1108/09727981111129336

Awasthi, A.; Chauhan, S. S. 2012. A hybrid approach integrating affinity diagram, AHP and fuzzy TOPSIS for sustainable city logistics planning, Applied Mathematical Modelling 36(2): 573-584. http://dx.doi.org/10.1016/j.apm.2011.07.033
Awasthi, A.; Chauhan, S. S.; Omrani, H. 2011a. Application of fuzzy TOPSIS in evaluating sustainable transportation systems, Expert Systems with Applications 38(10): 12270-12280. http://dx.doi.org/10.1016/j.eswa.2011.04.005

Awasthi, A.; Chauhan, S. S.; Omrani, H.; Panahi, A. 2011 b. A hybrid approach based on SERVQUAL and fuzzy TOPSIS for evaluating transportation service quality, Computers \& Industrial Engineering 61(3): 637-646. http://dx.doi.org/10.1016/j.cie.2011.04.019

Aydogan, E. K. 2011. Performance measurement model for Turkish aviation firms using the rough-AHP and TOPSIS methods under fuzzy environment, Expert Systems with Applications 38(4): 3992-3998.

http://dx.doi.org/10.1016/j.eswa.2010.09.060

Bascetin, A. 2004. An application of the analytic hierarchy process in equipment selection at Orhaneli open pit coal mine, Mining Technology 113(3): 192-199. http://dx.doi.org/10.1179/037178404225004968

Bazzazi, A. A.; Osanloo, M.; Karimi, B. 2011a. A new fuzzy multi criteria decision making model for open pit mines equipment selection, Asia-Pacific Journal of Operational Research 28(3): 279-300.

http://dx.doi.org/10.1142/S0217595911003247

Bazzazi, A. A.; Osanloo, M.; Karimi, B. 2011b. Deriving preference order of open pit mines equipment through MADM methods: application of modified VIKOR method, Expert Systems with Applications 38(3): 2550-2556. http://dx.doi.org/10.1016/j.eswa.2010.08.043

Belton, V.; Stewart, T. J. 2002. Multiple criteria decision analysis. Dordrecht: Kluwer Academic Publishers. 372 p. http://dx.doi.org/10.1007/978-1-4615-1495-4

Boender, C. G. E.; de Grann, J. G.; Lootsma, F. A. 1989. Multicriteria decision analysis with fuzzy pairwise comparison, Fuzzy Sets and Systems 29(2): 133-143. http://dx.doi.org/10.1016/0165-0114(89)90187-5

Boran, F. E.; Genç, S.; Kurt, M.; Akay, D. 2009. A multicriteria intuitionistic fuzzy group decision making for supplier selection with TOPSIS method, Expert Systems with Applications 36(8): 11363-11368.

http://dx.doi.org/10.1016/j.eswa.2009.03.039 
Buckley, J. J. 1985. Fuzzy hierarchical analysis, Fuzzy Sets and Systems 17(3): 233-247. http://dx.doi.org/10.1016/0165-0114(85)90090-9

Büyüközkan, G.; Çifçi, G. 2012. A combined fuzzy AHP and fuzzy TOPSIS based strategic analysis of electronic service quality in healthcare industry, Expert Systems with Applications 39(3): 2341-2354.

http://dx.doi.org/10.1016/j.eswa.2011.08.061

Chakraborty, S.; Banik, D. 2006. Design of a material handling equipment selection model using analytic hierarchy process, International Journal of Advanced Manufacturing Technology 28(11-12): 1237-1245. http://dx.doi.org/10.1007/s00170-004-2467-y

Chan, F. T. S.; Ip, R. W. L.; Lau, H. 2001. Integration of expert system with analytic hierarchy process for the design of material handling equipment selection system, Journal of Materials Processing Technology 116(2-3): 137-145. http://dx.doi.org/10.1016/S0924-0136(01)01038-X

Chang, D. Y. 1996. Applications of the extent analysis method on fuzzy AHP, European Journal of Operational Research 95(3): 649-655.

http://dx.doi.org/10.1016/0377-2217(95)00300-2

Chen, V. Y. C.; Lien, H. P.; Liu, C. H.; Liou, J. J. H.; Tzenge, G. H.; Yang, L. S. 2011. Fuzzy MCDM approach for selecting the best environment-watershed plan, Applied Soft Computing 11(1): 265-275. http://dx.doi.org/10.1016/j.asoc.2009.11.017

Cheng, C. H. 1996. Evaluating naval tactical missile systems by fuzzy AHP based on the grade value of membership function, European Journal of Operational Research 96(2): 343-350. http://dx.doi.org/10.1016/S0377-2217(96)00026-4

Chu, H. K.; Egbelu, P. J.; Wu, C. T. 1995. A computer aided material handling equipment selection system, International Journal of Production Research 33(12): 33113329. http://dx.doi.org/10.1080/00207549508904876

Denby, B.; Schofield, D. 1990. Applications of expert systems in equipment selection for surface mine design, International Journal of Surface Mining and Reclamation 4(4): 165-171. http://dx.doi.org/10.1080/09208119008944184

Fisher, E. L.; Farber, J. B.; Kay, M. G. 1988. MATHES: an expert system for material handling equipment selection, Engineering Costs and Production Economics 14(4): 297-310.

http://dx.doi.org/10.1016/0167-188X(88)90034-1

Fonseca, D. J.; Uppal, G.; Greene, T. J. 2004. A knowledgebased system for conveyor equipment selection, Expert Systems with Applications 26(4): 615-623. http://dx.doi.org/10.1016/j.eswa.2003.12.011

Fouladgar, M. M.; Yazdani-Chamzini, A.; Zavadskas, E. K. 2011. An integrated model for prioritizing strategies of the Iranian mining sector, Technological and Economic Development of Economy 17(3): 459-483. http://dx.doi.org/10.3846/20294913.2011.603173

Fouladgar, M. M.; Yazdani-Chamzini, A.; Lashgari, A.; Zavadskas, E. K.; Turskis, Z. 2012a. Maintenance strategy selection using AHP and COPRAS under fuzzy environment, International Journal of Strategic Property Management 16(1): 85-104. http://dx.doi.org/10.3846/1648715X.2012.666657

Fouladgar, M. M.; Yazdani-Chamzini, A.; Zavadskas, E. K. 2012b. Risk evaluation of tunneling projects, Archives of Civil and Mechanical Engineering 12: 1-12.
Fouladgar, M. M.; Yazdani-Chamzini, A.; Zavadskas, E. K.; Moini, S. H. H. 2012c. A new hybrid model for evaluating the working strategies: case study of construction company, Technological and Economic Development of Economy 18(1): 165-191. http://dx.doi.org/10.3846/20294913.2012.667270

Han, Z.; Liu, P. 2011. A fuzzy multi-attribute decision-making method under risk with unknown attribute weights, Technological and Economic Development of Economy 17(2): 246-258. http://dx.doi.org/10.3846/20294913.2011.580575

Hwang, C. L.; Yoon, K. 1981. Multiple attributes decision making methods and applications. Berlin: Springer. $259 \mathrm{p}$. http://dx.doi.org/10.1007/978-3-642-48318-9

Jolai, F.; Yazdian, S. A.; Shahanaghi, K.; Khojasteh, M. A. 2011. Integrating fuzzy TOPSIS and multi-period goal programming for purchasing multiple products from multiple suppliers, Journal of Purchasing \& Supply Management 17(1): 42-53. http://dx.doi.org/10.1016/j.pursup.2010.06.004

Kalibatas, D.; Zavadskas, E. K.; Kalibatiene, D. 2011. The concept of the ideal indoor environment in multi-attribute assessment of dwelling-houses, Archives of Civil and Mechanical Engineering 11(1): 89-101.

http://dx.doi.org/10.1016/S1644-9665(12)60176-9

Kara, S. S. 2011. Supplier selection with an integrated methodology in unknown environment, Expert Systems with Applications 38(3): 2133-2139. http://dx.doi.org/10.1016/j.eswa.2010.07.154

Karsak, E. E. 2002. Distance-based fuzzy MCDM approach for evaluating flexible manufacturing system alternatives, International Journal of Production Research 40(13): 3167-3181. http://dx.doi.org/10.1080/00207540210146062

Kulak, O. 2005. A decision support system for fuzzy multiattribute selection of material handling equipments, $E x$ pert Systems with Applications 29(2): 310-319. http://dx.doi.org/10.1016/j.eswa.2005.04.004

Kutlu, A. C.; Ekmekçioğlu, M. 2012. Fuzzy failure modes and effects analysis by using fuzzy TOPSIS-based fuzzy AHP, Expert Systems with Applications 39: 61-67. http://dx.doi.org/10.1016/j.eswa.2011.06.044

Lashgari, A.; Fouladgar, M. M.; Yazdani-Chamzini, A.; Skibniewski, M. J. 2011. Using an integrated model for shaft sinking method selection, Journal of Civil Engineering and Management 17(4): 569-580. http://dx.doi.org/10.3846/13923730.2011.628687

Lashgari, A.; Yazdani-Chamzini, A.; Fouladgar, M. M.; Zavadskas, E. K.; Shafiee, S.; Abbate, N. 2012. Equipment selection using fuzzy multi criteria decision making model: key study of Gole Gohar iron mine, Inzinerine Ekonomika - Engineering Economics 23(2): 125-136.

Liao, C. N.; Kao, H. P. 2011. An integrated fuzzy TOPSIS and MCGP approach to supplier selection in supply chain management, Expert Systems with Applications 38(9): 10803-10811. http://dx.doi.org/10.1016/j.eswa.2011.02.031

Liu, P. 2009. Multi attribute decision making method research based on interval vague set and TOPSIS method, Technological and Economic Development of Economy 15(3): 453-463. http://dx.doi.org/10.3846/1392-8619.2009.15.453-463 
Mahdavi, I.; Shirazi, B.; Sahebjamnia, N. 2011. Development of a simulation-based optimisation for controlling operation allocation and material handling equipment selection in FMS, International Journal of Production Research 49(23): 6981-7005. http://dx.doi.org/10.1080/00207543.2010.534826

Mirhosseyni, S. H. L.; Webb, P. 2009. A hybrid fuzzy knowledge-based expert system and genetic algorithm for efficient selection and assignment of material handling equipment, Expert Systems with Applications 36(9):

$11875-11887$.

http://dx.doi.org/10.1016/j.eswa.2009.04.014

Monjezi, M.; Bahrami, A.; Varjani, A. Y.; Sayadi, A. R. 2011. Prediction and controlling of flyrock in blasting operation using artificial neural network, Arabian Journal of Geosciences 4(3-4): 421-425. http://dx.doi.org/10.1007/s12517-009-0091-8

Onut, S.; Kara, S. S.; Mert, S. 2009. Selecting the suitable material handling equipment in the presence of vagueness, International Journal of Advanced Manufacturing Technology 44(7-8): 818-828. http://dx.doi.org/10.1007/s00170-008-1897-3

Paramasivam, V.; Senthil, V.; Ramasamy, N. R. 2011. Decision making in equipment selection: an integrated approach with digraph and matrix approach, AHP and ANP, International Journal of Advanced Manufacturing Technology 54(9-12): 1233-1244.

http://dx.doi.org/10.1007/s00170-010-2997-4

Park, Y. B. 1996. ICMESE: intelligent consultant system for material handling equipment selection and evaluation, Journal of Manufacturing Systems 15(5): 325-333. http://dx.doi.org/10.1016/0278-6125(96)84195-1

Poon, T. C.; Choy, K. L.; Cheng, C. K.; Lao, S. I.; Lam, H. Y. 2011. Effective selection and allocation of material handling equipment for stochastic production material demand problems using genetic algorithm, Expert Systems with Applications 38(10): 12497-12505.

http://dx.doi.org/10.1016/j.eswa.2011.04.033

Saaty, T. L. 1980. The analytical hierarchy process. New York: McGraw-Hill. 28 p.

Sayadi, A. R.; Lashgari, A.; Paraszczak, J. 2012. Hard-rock LHD cost estimation using single and multiple regressions based on principal component analysis, Tunnelling and Underground Space Technology 27(1): 133-141. http://dx.doi.org/10.1016/j.tust.2011.08.006

Sule, D. R. 1994. Manufacturing facilities: location, planning and design. $2^{\text {nd }}$ ed. Boston: PWS Publishing Company. $382 \mathrm{p}$.

Sun, C. C. 2010. A performance evaluation model by integrating fuzzy AHP and fuzzy TOPSIS methods, Expert Systems with Applications 37(12): 7745-7754. http://dx.doi.org/10.1016/j.eswa.2010.04.066

Tupenaite, L.; Zavadskas, E. K.; Kaklauskas, A.; Turskis, Z.; Seniut, M. 2010. Multiple criteria assessment of alternatives for built and human environment renovation, Journal of Civil Engineering and Management 16(2): 257266. http://dx.doi.org/10.3846/jcem.2010.30
Tuzkaya, G.; Gülsün, B.; Kahraman, C.; Özgen, D. 2010. An integrated fuzzy multi-criteria decision making methodology for material handling equipment selection problem and an application, Expert Systems with Applications 37(4): 2853-2863. http://dx.doi.org/10.1016/j.eswa.2009.09.004

Van Laarhoven, P. J. M.; Pedrycz, W. 1983. A fuzzy extension of Saaty's priority theory, Fuzzy Sets and Systems 11(13): 229-241. http://dx.doi.org/10.1016/S0165-0114(83)80082-7

Velury, J.; Kennedy, W. J. 1992. A systematic procedure for the selection of bulk material handling equipment, International Journal of Production Economics 27(3): 233-240. http://dx.doi.org/10.1016/0925-5273(92)90097-Q

Wang, Y. M.; Elhag, T. M. S. 2006. Fuzzy TOPSIS method based on alpha level sets with an application to bridge risk assessment, Expert Systems with Applications 31(2): 309319. http://dx.doi.org/10.1016/j.eswa.2005.09.040

Wang, Y. M.; Luo, Y.; Hua, Z. 2008. On the extent analysis method for fuzzy AHP and its applications, European Journal of Operational Research 186(2): 735-747. http://dx.doi.org/10.1016/j.ejor.2007.01.050

Wong, B. K.; Lai, V. S. 2011. A survey of the application of fuzzy set theory in production and operations management: 1998-2009, International Journal of Production Economics 129(1): 157-168. http://dx.doi.org/10.1016/j.ijpe.2010.09.013

Wu, C. S.; Lin, C. T.; Lee, C. 2010. Optimal marketing strategy: a decision-making with ANP and TOPSIS, International Journal of Production Economics 127(1): 190-196. http://dx.doi.org/10.1016/j.ijpe.2010.05.013

Yaman, R. 2001. A knowledge-based approach for selection of material handling equipment and material handling system pre-design, Turkish Journal of Engineering \& Environmental Sciences 25: 267-278.

Yazdani-Chamzini, A.; Yakhchali, S. H. 2012. Tunnel Boring Machine (TBM) selection using fuzzy multicriteria decision making methods, Tunnelling and Underground Space Technology 30: 194-204. http://dx.doi.org/10.1016/j.tust.2012.02.021

Yu, X.; Guo, S.; Guo, J.; Huang, X. 2011. Rank B2C ecommerce websites in e-alliance based on AHP and fuzzy TOPSIS, Expert Systems with Applications 38(4): 35503557. http://dx.doi.org/10.1016/j.eswa.2010.08.143

Yue, Z. 2011. Approach to group decision making based on determining the weights of experts by using projection method, Applied Mathematical Modelling 35(4): 19261936. http://dx.doi.org/10.1016/j.apm.2010.11.001

Zadeh, L. A. 1965. Fuzzy sets, Information and Control 8(3): 338-353. http://dx.doi.org/10.1016/S0019-9958(65)90241-X

Zavadskas, E. K.; Turskis, Z. 2011. Multiple criteria decision making (MCDM) methods in economics: an overview, Technological and Economic Development of Economy 17(2): 397-427. http://dx.doi.org/10.3846/20294913.2011.593291

\footnotetext{
Abdolreza YAZDANI-CHAMZINI. Master of Science in the Department of Strategic Management, Research Assistant of Fateh Reaserch Group, Tehran-Iran. Author of more than 20 research papers. In 2011 he graduated from the Science and Engineering Faculty at Tarbiat Modares University, Tehran-Iran. His research interests include decision making, forecasting, modeling, and optimization.
} 